Working Paper n. 12 - 2010

\title{
CONSUMERS' REACTIONS TO NEGATIVE INFORMATION ON PRODUCT QUALITY: EVIDENCE FROM SCANNER DATA
}

\author{
Maria De Paola \\ Dipartimento di Economia e Statistica \\ Università della Calabria \\ Ponte Pietro Bucci, Cubo 1/C \\ Tel.: +390984 492459 \\ Fax: +390984 492421 \\ e-mail:m.depaola@unical.it
}

Vincenzo Scoppa

Dipartimento di Economia e Statistica Università della Calabria Ponte Pietro Bucci, Cubo 1/C

Tel.: +390984 492464

Fax: +390984 492421

e-mail: v.scoppa@unical.it

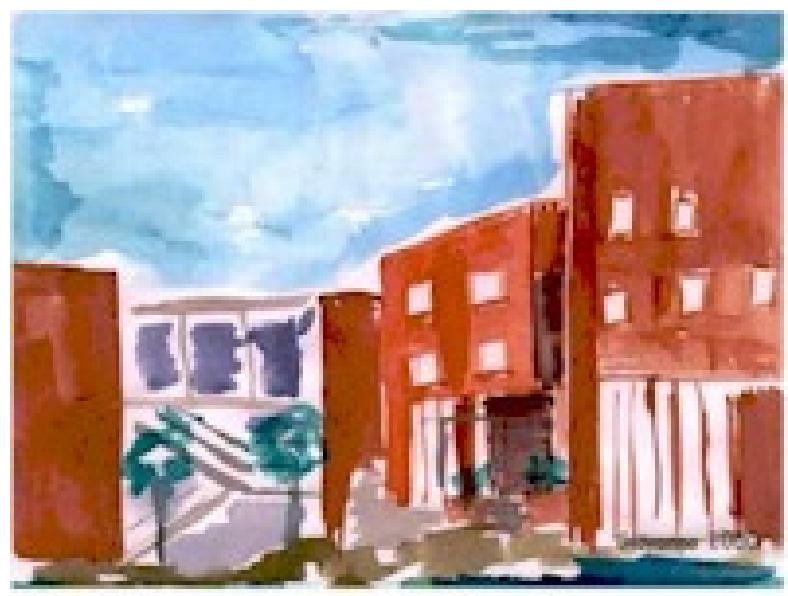




\title{
Consumers' Reactions to Negative Information on
}

\section{Product Quality: Evidence from Scanner Data}

\author{
Maria De Paola, Vincenzo Scoppa* \\ Department of Economics and Statistics, University of Calabria, Italy
}

\begin{abstract}
We analyze consumers' reactions to negative information on product quality using daily scanner data at item level from a well-known supermarket chain. We focus on a fraud that in 2008 has involved a number of Italian leading firms in the cheese sector. Exploiting the fact that only some brands were mentioned by the media as being involved in the fraud, we adopt a difference-in-differences estimation strategy and evaluate the effects of the negative media coverage comparing changes in sales for involved and for not involved brands. It emerges that the negative news on product quality have induced consumers to shift their demand from involved to not involved brands. These effects persist overtime, also once the media was no more giving attention to the issue. Retailers have suffered part of the costs deriving from the diffusion of bad news on product quality: the margin gained on brands directly mentioned by media has decreased after the negative publicity.
\end{abstract}

Keywords: Consumer Behavior, Product Quality; Firm Reputation; Scanner Data.

JEL classification: L14; L15; L66; Q11.

\section{Introduction}

Food markets - as many other markets - are generally characterized by informational asymmetries on product quality: while quality is well-known to the producer, consumers cannot evaluate fully and accurately the product they buy. In many cases consumers are not able to find out the true quality of the product even after consumption. For these reasons, food products can be classified as experience or credence goods (Nelson, 1974; Shapiro, 1983; Darby and Karni, 1973).

The asymmetries of information characterizing these markets give to the sellers the opportunity to exploit consumers, producing low quality products and selling them at a price above the cost. As described in the theoretical framework proposed by Klein and Leffler (1981) and Shapiro (1983), the working of markets afflicted by asymmetric information is mainly based on reputational mechanisms. The incentives for firms to produce high-quality goods arise from the reputational costs imposed upon firms responsible for selling low quality or unsafe products: consumers would switch

\footnotetext{
*E-mail addresses: m.depaola@unical.it; v.scoppa@unical.it. We would like to thank Antonio Ventriglia for providing access to the data and Alessandra Antonelli, Antonio Nicita, Michela Ponzo for useful comments.
} 
their demand away from opportunistic firms and the latter would lose the stream of rents on future sales.

The reputational mechanism relies upon the information available to consumers and in modern economies a crucial role is played by the transmission of information through the media. In fact, by reaching a broad population, mass media can alleviate informational frictions. It is, therefore, important to provide evidence on how consumers react to the news on product quality and on the consequences that their behavior imposes on producers. This has also crucial implications for the role of product-safety regulation and other consumer protection legislations: if markets are able to discipline opportunistic firms, imposing on them substantial costs, there is less need for this type of regulations.

The risks related to the consumption of "credence goods" explain the great attention that is reserved to articles in the press focusing on the health concerns deriving form different food hazards. The news reported by the media on product quality tend to influence consumers' perceptions and to affect their behavior. Negative publicity in the newspapers can cause a drop in consumer trust and produce long lasting negative effects on demand. On the other hand, it is also important to consider that since the news reported by the press are often based on rumors, a firm reputation may result damaged by negative publicity even in absence of an effective responsibility in the negative event receiving media coverage. Journalists and editors tend to highlight some views and marginalize other, also because of space limitations. This can result in ambiguous information and lead to negative effects also in absence of an effective health risk. In addition, as consumers tend to weight more negative information than positive information, it is generally difficult for firms to recover from negative media coverage.

Due to the increasing complexity of products, more stringent product-safety legislation and more demanding consumers, product-harm crises are becoming a recurrent event in modern economies. In some cases such type of crisis involved a whole sector (notable examples include a number of meat safety crises, hormone abuse, antibiotic residues, mad cow disease (BSE), etc.), while in others cases only one or a few brands were involved (airlines experiencing accidents; auto and pharmaceutical producers announcing recalls of defective products, etc.).

A number of works have tried to analyze the effects of product quality information on consumer demand and stock prices. However, results are not univocal. Jarrell and Peltzman (1985) find that the capital market penalizes considerably producers of recalled drugs and cars and the costs for the shareholders are greater than the costs directly related to the recalls, probably because of the loss of the firm goodwill. They show that competitor brands are also negatively affected, since the favorable effect on the demand for substitutes seems to be compensated by a negative effect on the whole industry. Borenstein and Zimmerman (1988), analyzing the effects of airline accidents, show that crashes are associated with statistically significant losses in equity value, but the negative events seem to produce rather weak responses from consumers. Moreover, it does not emerge any negative or 
positive externality on other firms in the industry. Garber and Adams (1998) find that product liability verdicts against automobile producers in US have a weak impact on the value of the firm and on product sales, probably because the verdicts carry little new information to consumers (since relevant information has already been revealed before the verdict). On the other hand, Prince and Rubin (2002) examine the effects of product liability litigation on firms in the automobile and pharmaceutical industries, focusing on the initial announcement of a liability problem. They show significant losses in the firm value. Analogous findings are shown by Viscusi and Hersch (1990) who analyze the impact of 29 product liability lawsuits reported in the Wall Street Journal from 1970-1985. In a similar vein, Takaoka (2004), focusing on the impact of product liability verdicts on the value of firms in Japan, finds that the amount of exposure the verdict receives in the newspaper leads to a significant fall in the firm's stock price.

A number of other works have analyzed the effects of safety information on food demand. Schlenker and Villas-Boas (2008) find a significant reduction in beef sales (and in cattle future prices) following the discovery of an infected cow in 2003 and a health warning in a TV show. Smith et al. (1988) analyze the impact of an incident involving milk contamination and find that negative media coverage has a large impact on purchases. On the other hand, Dahlgran and Fairchild (2002), analyzing the effects of the adverse publicity about food contamination through TV and print news coverage, show a negative but small effect on demand. From their analysis it also emerges that consumers have soon forgotten this negative publicity and revert back to previous consumption levels. Shimshack, Ward, and Beatty (2007), studying the effects of public warnings by the Food and Drug Administration on mercury in fish, show that consumers' responses are affected by socio-economic aspects. In particular, consumers with high educational level and readers of newspapers react more, suggesting the key role of information acquisition.

Our work contributes to this literature analyzing consumers' reactions to negative news concerning the quality of cheese of some Italian brands. On the $4^{\text {th }}$ July 2008, the Italian newspaper "La Repubblica"1 (followed by other newspapers and TV news) reported the results of an investigation (started in 2006) by a special police unit that has discovered that a number of companies - mainly based in Italy - reworked rotten or out-of-date cheese instead of destroying it. The rotten cheese was mixed with fresh products and resold, basically under the form of grated cheese. A number of wellknown cheese brands, such as Ferrari, Galbani, Prealpi, Soresina, were mentioned in the press as being involved in the scandal.

Consumers' reaction to these news are of key interest to understand the working of product markets under asymmetric information and the efficacy of reputational mechanisms. In principle, consumers may respond to the negative news on product quality in different ways. They may interpret the news as evidence that the grated cheese category is not safe and reduce their demand for the whole product category. On the other hand, they may interpret the information just in relation to brands

1 "La Repubblica” is the second largest circulation Italian newspaper. 
directly involved and switch their purchases from involved brands to not involved brands. Finally, consumers may exhibit little reaction, either because they do not pay attention to this type of news or because this information was already included in their beliefs about product quality.

To analyze consumers' reactions to these news, we use scanner data recording daily consumers' purchases, before, during and after the negative news on cheese quality. Data are from an Italian supermarket chain and cover the period from the $1^{\text {st }}$ January 2005 to the $31^{\text {st }}$ December 2009. Among the grated cheese product category we observe 40 items produced by 17 different brands. Four of these brands were involved in the scandal, while the remaining 13 were not directly affected by the negative publicity. This allows us to identify a treatment and a control group and to estimate the effects of the negative media attention on purchased quantities by using a difference-in-differences estimation strategy. By comparing consumers' purchases of the two groups of brands, we disentangle the effects of the scandal from common temporal trends that may have affected consumer choices.

We investigate consumers' responses both in the short and in the medium-run. To examine the short-run effects of the negative media coverage we have used three different indicators: a dummy variable for the period during which the fraud received media attention (essentially from July 2008 to October 2008) and two indexes based on the Google search engine considering, respectively, the number of articles in the press related to the fraud and the number of Google searches made in Italy about the cheese scandal. Controlling for item and store fixed effects, seasonal factors, prices, yearly dummies, daily revenues of each store, we find a significant reduction of consumers' purchases of the brands affected by the negative publicity and an increase in the sales of brands that were not directly mentioned by the media.

As far as medium-run effects are concerned, from our analysis it emerges that the negative impact deriving from the loss of consumers' "goodwill” persists over time. Our estimates show that even after a year since the negative news on product quality were reported by the media, consumers continue to show a lower demand for involved brands’ products.

We also find that consumers' reactions differ according to their socio-economic characteristics: consumers living in richer areas have reduced their demand for the whole product category, while those living in poorer areas seem to have switched purchases from involved brands to not involved brands.

Finally, we also investigate how the negative publicity has affected retailer prices and margins obtained by retailers. We show that, in spite of an increasing trend in prices, items produced by the brands affected by the negative media coverage show a much smaller increase compared to the brands not involved in the fraud. Moreover, from our analysis it emerges that part of the costs deriving from the negative publicity were directly borne by the retailers, since after the fraud they realize lower margins on the involved brands.

The paper is organized as follows. In Section 2 we provide some details on the cheese fraud considered in our analysis and on the news reported by the media. In this section we also describe the 
scanner data used in the econometric analysis. In Section 3 we investigate the immediate response of demand to negative media coverage. Section 4 is devoted to the analysis of the medium-run effects. In Section 5 we present the results concerning changes in retailer prices and margins. Section 6 presents some robustness checks. Section 7 offers some concluding remarks.

\section{Data and Descriptive Statistics}

To analyze consumers' reactions to negative news on product quality we focus our attention on a fraud that took place in Italy and involved the cheese sector. From the $4^{\text {th }}$ July 2008 to the $18^{\text {th }}$ October 2008, a number of articles were published in the Italian press reporting about a policy investigation on some dairies reworking out-of-date and rotten cheese. According to the news, 11,000 tons of rotten cheese were mixed with fresh products and sold to consumers, mainly as grated cheese. Three people have been arrested, while a dozen more suspects are still under investigation. The factories were closed in June 2008. Since the Italian authorities remained confident that the reworked cheese did not pose a risk to consumer safety, the fraud has not led to product recall.

The Italian newspaper La Repubblica reported that a number of well-known brands were involved in the scandal (Ferrari, Galbani, Prealpi, Soresina). This information was diffused also in a number of other articles in the press and in several television broadcasting news services. The news reported by the media on the role played by these brands in the fraud were rather vague: in many articles these brands were mentioned as involved in the fraud either as firms commercializing the reworked cheese or as dairies providing the out-of-date cheese to the main responsible of the fraud. ${ }^{2}$

The reprocessed rotten cheese was mainly used to make cheese spreads and grated cheese. We focus exclusively on grated cheese, since this product category is sold by a large number of brands and we are able to distinguish between brands receiving negative publicity and brands that were not directly involved. In contrast, cheese spreads in Italy are mainly sold by one leading brand and we are not able to investigate consumer decisions to switch from one brand to another.

Our analysis is based on scanner data provided by Despar, a large Italian supermarket chain. ${ }^{3}$ Our data come from 17 stores operating in Rome and in some neighboring towns and provide information on daily purchases concerning 40 different items, belonging to the category "Grated Cheese”, commercialized by 17 different brands and covering the period going from the $1^{\text {st }}$ January 2005 to the $31^{\text {st }}$ December 2009.

The dataset includes for each day the price and the quantity sold at item and store level, a binary indicator if the item is on special offer, the items produced by each brand, the total revenues by store, the cost of each item for the retailer (i.e. the price paid by Despar to producers). On the other

\footnotetext{
${ }^{2}$ These brands have declared to have no responsibility in the fraud and since the investigation is still open it is not possible to know their real involvement.

${ }^{3}$ Despar has 1.838 affiliated stores in Italy.
} 
hand, we do not have information on individual customers' attributes such as income, occupation, age, educational level, etc.

The use of these data allows us to investigate how consumers reacted to the bad publicity deriving from the cheese scandal distinguishing the impact on different brands, since only some of them were mentioned by the media as being involved in the fraud. Other data sources, such as the Household Consumption Survey provided by the National Institute of Statistics (ISTAT), which provide data for aggregated product categories - in our case for the whole cheese category - would not allow this type of analysis.

Thanks to the information we have on the retailer price of each item, we are able to control for this variable and to disentangle the effects of negative media coverage from the variations originated by price changes (which, as we will show in section 5, tend to be correlated with the adverse publicity).

Since grated cheese is sold in packages of different weight, we measure the quantity sold in terms of grams and instead of considering the price of each piece sold we calculate the price per gram by dividing the price for the product weight.

We have available about 154,000 observations at the daily-store-item level (5 years*17 stores*40 items). Note that not all items are sold in every store. Moreover, we have no data if an item in a given store and in a given day is not sold at least once.

The 40 items are produced by 17 different brands. Among them, 4 brands - producing 10 items - were involved in the scandal. Table 1 provides some descriptive statistics. About 38\% of transactions refer to involved brands. 32\% of transactions recorded in our dataset concern the period after the negative media coverage. On average, quantity sold is equal to 905 grams, average price is $€ 14.9$ per kilogram. About $6.8 \%$ of items sold each day are on special offer. The average daily revenues for stores in our dataset are of $€ 18,235$.

Table 1. Descriptive Statistics

\begin{tabular}{lccccc}
\hline Variables & Mean & Std. Dev & Min. & Max. & Obs. \\
\hline Quantity in grams & 905.4326 & 1315.2780 & 60 & 60100 & 154617 \\
Price (€) per gram & 0.0149 & 0.0059 & 0.0035 & 0.0417 & 154619 \\
Media Coverage Period & 0.0607 & 0.2388 & 0 & 1 & 154619 \\
Google News & 0.9604 & 3.8538 & 0 & 20 & 154619 \\
Google Searches & 2.0304 & 11.1058 & 0 & 100 & 154619 \\
Google News*(Involved Brands) & 0.3222 & 2.2632 & 0 & 20 & 154619 \\
Special Offer & 0.0685 & 0.2526 & 0 & 1 & 154619 \\
Total Revenues & 18235.1 & 18136.9 & 326.81 & 185636.7 & 154619 \\
Post & 0.3248 & 0.4683 & 0 & 1 & 154619 \\
Involved Brands & 0.3851 & 0.4866 & 0 & 1 & 154619 \\
Post*(Involved Brands) & 0.1111 & 0.3142 & 0 & 1 & 154619 \\
House Price (€ for squared meter) & 4534.2210 & 2418.4070 & 1150 & 8500 & 154619 \\
\hline Notes: Scanner data at daily-store-item level from the 1st January 2005 to the 31st December 2009. Google News and \\
Google Searches are built using the Google search engine. House prices are taken from an agency of the Italian Ministry \\
of Economy monitoring house market.
\end{tabular}




\section{Short-run Consumers' Reactions to the Negative Media Coverage}

In order to analyze the effects that the negative media coverage may have produced on consumer behavior we adopt a difference-in-differences estimation strategy exploiting the fact that only a certain number of brands were exposed at a certain point of time to direct negative media coverage. Before the cheese fraud was reported by the media, none of the groups was exposed to the "treatment". On the other hand, after the $4^{\text {th }}$ July 2008 only some brands get directly exposed. Therefore, we consider as treatment group those brands that were mentioned by the press as being involved in the cheese scandal (“Involved Brands”), whereas we consider as control group those brands that did not receive directly negative publicity ("Not Involved Brands"). The difference-in-differences estimation method allows us to estimate the causal effect of the direct negative media coverage by comparing the changes in the average sales of "Involved Brands" with the changes in the average sales of "Not Involved Brands". A key identification assumption is that brand-specific trends in the outcome of interest would be identical in the absence of treatment.

Firstly, we examine the short-run effects of the negative publicity simply comparing the changes in the average sales of the brands in the treatment and in the control group during the period of time the cheese fraud received media attention.

More precisely, we estimate several specifications of the following model:

$$
\begin{aligned}
\ln \left(Q_{i j t}\right) & =\beta_{0}+\beta_{1} \text { MediaCoverage }_{t}+\beta_{2}\left(\text { MediaCoverage }_{t} * \text { InvolvedBrands }_{i}\right)+ \\
& +\beta_{3} \ln \left(P_{i j t}\right)+\beta_{4} X_{i j t}+\lambda_{i}+\mu_{j}+\gamma_{t}+\varepsilon_{i j t}
\end{aligned}
$$

where $\ln \left(Q_{i j t}\right)$ is the natural $\log$ of the quantity (in grams) of grated cheese of item $i$ sold by the store $j$ in day $t$, MediaCoverage ${ }_{t}$ is a measure of the attention devoted by the media to the cheese fraud; MediaCoverage $_{t}{ }^{*}$ InvolvedBrands $_{i}$ is an interaction term between MediaCoverage $_{t}$ and InvolvedBrands $_{i}$; the latter is a dummy variable for items produced by brands directly affected by the negative publicity, $\ln \left(P_{i j t}\right)$ is the natural $\log$ of the price (per gram) of item $i$ in store $j$ at time $t, X_{i j t}$ is a vector of control variables including total per day revenues of store $j$ and a dummy for products on special offers, $\lambda_{i}$ is a vector of item dummies (40), $\mu_{j}$ a vector of store dummies (17), $\gamma_{t}$ are dummies for day of the week, month of the year and year, $\varepsilon_{i j t}$ is an error term.

To measure the attention devoted by the media and by the consumers to the fraud and build our variable MediaCoverage $_{t}$ we have used three indicators: a dummy variable for the period during which the fraud received media attention (taking the value of 1 from the $4^{\text {th }}$ July 2008 to the $18^{\text {th }}$ 
October 2008 and 0 otherwise) and two indexes based on the Google Search Engine. ${ }^{4}$ The first index uses Google News, which is a computer-generated news site that aggregates headlines from news sources worldwide. ${ }^{5}$ In detail, we have considered the number of articles in the press appearing on line in Italy and related to the cheese fraud. The second index, Google Searches, is based on "Google Insights for Search", ${ }^{6}$ which allows to compute search volume patterns for a given query (providing weekly data). More precisely, we consider the number of searches that have been done in Italy for the term "cheese fraud" relative to the total number of searches done on Google over time. This index is normalized and takes values between 0 and 100, where a value equal to 100 represents the maximum number of searches recorded during the selected time period.

In Table 2 are reported fixed effects estimates. The dependent variable is represented by the natural $\log$ of the quantity of grated cheese of item $i$ sold by the store $j$ in day $t$. In all specifications standard errors are clustered at item level and are robust to heteroskedacity.

We find a statistically significant reduction of consumer purchases of brands directly affected by the negative publicity and an increase in sales of brands that were not mentioned by the media. As it is possible to see in column (1), in which we measure the attention received by the fraud using the dummy variable for the period during which the fraud had received media attention (from the $4^{\text {th }}$ July 2008 to the $18^{\text {th }}$ October 2008), the coefficient on the dummy variable (measuring the impact on Not Involved Brands) is positive and statistically significant, while the interaction term MediaCoverage $_{t}{ }^{*}$ InvolvedBrands $_{i}$ is negative and statistically significant at the 1 percent level. Therefore, these results show that sales of involved brands have decreased, since the sum between the coefficient on MediaCoverage $e_{t}$ and that on MediaCoverage ${ }_{t}^{*}$ InvolvedBrands $_{i}$ is negative and statistically significant.

In columns 2 we investigate whether consumers' reactions are related to the extent of news coverage using the variable Google News and its interaction with "Involved Brands". Results show that the higher the news coverage, the lower are the sales of involved brands, while the higher are the sales of not involved brands. Very similar results are obtained in column 3 using the index Google Searches that represents a proxy of the consumers' interest in the scandal.

Estimation results imply that during the period in which the fraud has received media and consumer attention, sales for "Not Involved Brands" have increased, while those of "Involved Brands" have decreased. Consumers on average have reacted to the negative news on product quality substituting items sold by involved brands with products sold by not involved brands.

\footnotetext{
${ }^{4}$ An increasing number of works is relying on this type of indexes to measure economic and social behavior. For example, the Google Index proved to have predictive power in forecasting unemployment developments in Germany (Askitas and Zimmermann, 2009), Israel (Suhoy, 2009) and United States (Choi and Varian, 2009; D’Amuri and Marcucci, 2009). See also Ginsberg et al. (2009).

${ }^{5}$ See http://news.google.it/

${ }^{6}$ See http://www.google.com/insights/search/
} 
As far as other variables are concerned, it emerges that the sales of each item react negatively and strongly to the item price, showing an elasticity of 1.33. Items on price promotions show higher sales even controlling for price. On the other hand, sales turn out to be significantly lower if competitor items are on special offer. Yearly dummies show that sales of grated cheese have increased from 2005 to 2009. Purchases are higher during the winter and increase on Saturday (dummies for days of the week and months of the year are not reported in the Tables to save space). ${ }^{7}$

Table 2. The short-run consumers' responses to negative media coverage. Dependent Variable: the natural log of the quantity of grated cheese

\begin{tabular}{|c|c|c|c|c|c|c|}
\hline & \multicolumn{3}{|c|}{ Period: 2005-2009 } & \multicolumn{3}{|c|}{ Period: 2005-2009 } \\
\hline & (1) & (2) & (3) & (4) & (5) & (6) \\
\hline Price per gram (in log) & $\begin{array}{c}-1.332 * * * \\
(0.022)\end{array}$ & $\begin{array}{c}-1.331 * * * \\
(0.022)\end{array}$ & $\begin{array}{c}-1.331 * * * \\
(0.022)\end{array}$ & $\begin{array}{c}-1.222 * * * \\
(0.027)\end{array}$ & $\begin{array}{c}-1.220^{* * *} \\
(0.027)\end{array}$ & $\begin{array}{c}-1.220 * * * \\
(0.027)\end{array}$ \\
\hline Media Coverage Period & $\begin{array}{c}0.075^{* * *} \\
(0.010)\end{array}$ & & & $\begin{array}{c}0.094 * * * \\
(0.011)\end{array}$ & & \\
\hline $\begin{array}{l}\text { (Media Coverage Period) } \\
\text { *(Involved Brands) }\end{array}$ & $\begin{array}{c}-0.093^{* * *} \\
(0.015)\end{array}$ & & & $\begin{array}{c}-0.071^{* * *} \\
(0.015)\end{array}$ & & \\
\hline Google News & & $\begin{array}{c}0.004^{* * *} \\
(0.001)\end{array}$ & & & $\begin{array}{c}0.004^{* * *} \\
(0.001)\end{array}$ & \\
\hline (Google News)*(Involved Brands) & & $\begin{array}{c}-0.006 * * * \\
(0.001)\end{array}$ & & & $\begin{array}{c}-0.004 * * * \\
(0.001)\end{array}$ & \\
\hline Google Searches & & & $\begin{array}{c}0.001^{* * *} \\
(0.000)\end{array}$ & & & $\begin{array}{c}0.001 * * * \\
(0.000)\end{array}$ \\
\hline (Google Searches)*(Involved Brands) & & & $\begin{array}{l}-0.002^{* * *} \\
(0.000)\end{array}$ & & & $\begin{array}{c}-0.001 * * * \\
(0.000)\end{array}$ \\
\hline Special Offer & $\begin{array}{c}0.256 * * * \\
(0.011)\end{array}$ & $\begin{array}{c}0.256^{* * *} \\
(0.011)\end{array}$ & $\begin{array}{l}0.256^{* * *} \\
(0.011)\end{array}$ & $\begin{array}{l}0.285^{* * *} \\
(0.012)\end{array}$ & $\begin{array}{c}0.286 * * * \\
(0.012)\end{array}$ & $\begin{array}{c}0.285^{* * *} \\
(0.012)\end{array}$ \\
\hline Special Offer Other Products & $\begin{array}{l}-0.071 * * * \\
(0.004)\end{array}$ & $\begin{array}{c}-0.071^{* * *} \\
(0.004)\end{array}$ & $\begin{array}{c}-0.070^{* * *} \\
(0.004)\end{array}$ & $\begin{array}{l}-0.096 * * * \\
(0.005)\end{array}$ & $\begin{array}{c}-0.096 * * * \\
(0.005)\end{array}$ & $\begin{array}{c}-0.096 * * * \\
(0.005)\end{array}$ \\
\hline Year 2006 & $\begin{array}{c}0.069 * * * \\
(0.007)\end{array}$ & $\begin{array}{c}0.069 * * * \\
(0.007)\end{array}$ & $\begin{array}{c}0.069 * * * \\
(0.007)\end{array}$ & & & \\
\hline Year 2007 & $\begin{array}{c}0.076 * * * \\
(0.007)\end{array}$ & $\begin{array}{c}0.076 * * * \\
(0.007)\end{array}$ & $\begin{array}{c}0.077 * * * \\
(0.007)\end{array}$ & & & \\
\hline Year 2008 & $\begin{array}{c}0.113^{* * *} \\
(0.007)\end{array}$ & $\begin{array}{c}0.117 * * * \\
(0.007)\end{array}$ & $\begin{array}{c}0.121 * * * \\
(0.007)\end{array}$ & $\begin{array}{c}0.026 * * * \\
(0.006)\end{array}$ & $\begin{array}{c}0.034^{* * *} \\
(0.006)\end{array}$ & $\begin{array}{c}0.042^{* * *} \\
(0.006)\end{array}$ \\
\hline Year 2009 & $\begin{array}{c}0.093 * * * \\
(0.007)\end{array}$ & $\begin{array}{c}0.093 * * * \\
(0.007)\end{array}$ & $\begin{array}{c}0.093 * * * \\
(0.007)\end{array}$ & $\begin{array}{c}0.007 \\
(0.006)\end{array}$ & $\begin{array}{c}0.006 \\
(0.006)\end{array}$ & $\begin{array}{c}0.006 \\
(0.006)\end{array}$ \\
\hline Constant & $\begin{array}{c}0.911^{* * *} \\
(0.100)\end{array}$ & $\begin{array}{c}0.911^{* * *} \\
(0.100)\end{array}$ & $\begin{array}{c}0.910 * * * \\
(0.100)\end{array}$ & $\begin{array}{l}1.381^{* * *} \\
(0.119)\end{array}$ & $\begin{array}{l}1.387 * * * \\
(0.119)\end{array}$ & $\begin{array}{l}1.387 * * * \\
(0.119)\end{array}$ \\
\hline Observations & 154617 & 154617 & 154617 & 100361 & 100361 & 100361 \\
\hline R-squared & 0.257 & 0.257 & 0.257 & 0.244 & 0.243 & 0.243 \\
\hline Number of items & 40 & 40 & 40 & 29 & 29 & 29 \\
\hline
\end{tabular}

In columns 4, 5 and 6 we replicate the same specifications of, respectively, columns 1, 2 and 3 , but we consider a different time window. In these estimates we have excluded from our sample the observations for the period before the $1^{\text {st }}$ January 2008 and we have focused exclusively on the years 2008 and 2009. This choice has been made to avoid the comparison of consumers' purchases taking place in very different periods of time. However, results do not change significantly: it emerges again

\footnotetext{
${ }^{7}$ Similar results are obtained when we control for the total daily revenues of the store. As expected, sales increase with the total revenues, which is an indicator of the number of customers visiting the store each day (the same results are obtained when we measure total demand with the number of daily fiscal tickets).
} 
that during the period in which the negative news on product quality were reported by the media, sales have increased for brands not directly mentioned in newspapers and decreased for those receiving negative publicity.

\section{Do Consumers' Reactions Persist Over Time?}

In this section we investigate whether the effects deriving from the diffusion of negative news on product quality persist over time, also when the issue is no more receiving media attention. To this aim we estimate the following model:

$$
\ln \left(Q_{i j t}\right)=\beta_{0}+\beta_{1} \text { Post }_{t}+\beta_{2}\left(\text { Post }_{t}^{*} \text { InvolvedBrands }_{i}\right)+\beta_{3} \ln \left(P_{i j t}\right)+\beta_{4} X_{i j t}+\lambda_{i}+\mu_{j}+\gamma_{t}+\varepsilon_{i j t}
$$

in which instead of focusing on the period during which the media has devoted attention to the fraud, we consider the whole period after the fraud news had reached the first pages of Italian newspapers. The dummy Post $t_{t}$ takes the value of one for the period after the $4^{\text {th }}$ July 2008 and zero otherwise, while Post $_{t}{ }^{*}$ InvolvedBrands ${ }_{i}$ is the interaction term, whose coefficient measures the treatment effect of our interest.

Table 3 reports estimation results. From the results reported in column 1 it emerges that after the $4^{\text {th }}$ July 2008 consumers' purchases have increased for “Not Involved Brands” of about 10 percent (the dummy Post $t_{t}$ is positive and statistically significant at the 1 percent level). On the other hand, the coefficient on the interaction term Post $_{t}{ }^{*}$ InvolvedBrands $_{i}$ is negative and highly statistically significant. The sum of these two coefficients is negative $(-0.062)$ and statistically significant implying that sales for the "Involved Brands" have decreased after the negative media coverage (see column 1).

Since the uncovered negative effect on involved brands might be driven by the impact that the bad news had in the short run, in column 2 we have excluded from our sample the observations for the period going from the $4^{\text {th }}$ July 2008 to the $18^{\text {th }}$ October 2008. Again the dummy Post $t_{t}$ is positive and highly significant, while the interaction term Post $_{t}{ }^{*}$ InvolvedBrands $s_{i}$ is negative. The net effect for Involved Brands is a reduction of sales of 8.2 percent, highly statistically significant ( $t$-stat $=-10.90)$. From this finding it emerges that the medium-run effects of negative media coverage are stronger than short-run effects, maybe because it takes time for the information to disseminate among consumers.

In column 3 we include among our regressors - instead of the dummy Post $_{t}-$ a temporal variable Trend $_{t}$ and three different interactions terms: Trend $_{t}{ }^{*}$ InvolvedBrands $_{i}$, Trend $_{t}{ }^{*}$ Post $_{t}$ and 
Trend $_{t} *$ InvolvedBrands $_{i} *$ Post $_{t} .{ }^{8}$ The coefficient on the dummy Trend $_{t}$ describes the temporal trend of the demand for items produced by "Not Involved Brands" before the $4^{\text {th }}$ July 2008. The coefficient is positive and statistically significant suggesting that the demand for these items was rising over time until July 2008. The coefficient on Trend $_{t}{ }^{*}$ InvolvedBrands $_{i}$ is not statistically significant, implying that before July 2008 the temporal pattern for items produced by "Involved Brands” was similar to that observed for items produced by "Not Involved Brands". Interestingly, the coefficient on the interaction term Trend $_{t}{ }^{*}$ InvolvedBrands $_{i}{ }^{*}$ Post $_{t}$ is negative and highly statistically significant, implying that after the negative media coverage, the brands directly affected by the negative media coverage show a decreasing trend in demand. No such a negative effect is detected for brands not directly involved in the fraud: the coefficient on the interaction term Trend $_{t}{ }^{*}$ Post $_{t}$ is positive, suggesting that sales for these brands have continued to show a positive pattern (slightly higher than before July 2008).

In columns 4, 5 and 6 we replicate the same specifications discussed above but we exclude from our sample observations for the period before the $1^{\text {st }}$ January 2008, with the aim of comparing transactions taking place in a more homogenous period of time. Results remain substantially unchanged.

All in all these estimates suggest that the effects of the negative media coverage persist over time and they are more pronounced in the medium-run than in the short-run.

Table 3. The medium-run consumers' responses to negative media coverage. Dependent Variable: the natural log of the quantity of grated cheese

\begin{tabular}{|c|c|c|c|c|c|c|}
\hline & (1) & (2) & (3) & (4) & (5) & (6) \\
\hline Price per gram (in log) & $\begin{array}{c}-1.317 * * * \\
(0.022)\end{array}$ & $\begin{array}{c}-1.279 * * * \\
(0.023)\end{array}$ & $\begin{array}{c}-1.376^{* * *} \\
(0.023)\end{array}$ & $\begin{array}{c}-1.274^{* * *} \\
(0.027)\end{array}$ & $\begin{array}{c}-1.232^{* * *} \\
(0.029)\end{array}$ & $\begin{array}{c}-1.251^{* * *} \\
(0.027)\end{array}$ \\
\hline Post & $\begin{array}{c}0.099 * * * \\
(0.005)\end{array}$ & $\begin{array}{c}0.089 * * * \\
(0.006)\end{array}$ & & $\begin{array}{c}0.069 * * * \\
(0.006)\end{array}$ & $\begin{array}{c}0.053^{* * *} \\
(0.007)\end{array}$ & \\
\hline Post*(Involved Brands) & $\begin{array}{c}-0.161^{* * *} \\
(0.008)\end{array}$ & $\begin{array}{c}-0.171^{* * *} \\
(0.009)\end{array}$ & & $\begin{array}{c}-0.123 * * * \\
(0.010)\end{array}$ & $\begin{array}{c}-0.129 * * * \\
(0.011)\end{array}$ & \\
\hline Trend & & & $\begin{array}{c}0.092^{* * * *} \\
(0.008)\end{array}$ & & & $\begin{array}{c}-0.010 \\
(0.021)\end{array}$ \\
\hline Trend Post & & & $\begin{array}{c}0.012 * * \\
(0.005)\end{array}$ & & & $\begin{array}{c}0.037 * * * \\
(0.008)\end{array}$ \\
\hline (Trend)*Involved Brands & & & $\begin{array}{c}-0.003 \\
(0.013)\end{array}$ & & & $\begin{array}{c}-0.072 * * \\
(0.034)\end{array}$ \\
\hline (Trend)*(Post)*Involved Brands & & & $\begin{array}{c}-0.101^{* * *} \\
(0.009)\end{array}$ & & & $\begin{array}{c}-0.049 * * * \\
(0.014)\end{array}$ \\
\hline Special Offer & $\begin{array}{c}0.255^{* * *} \\
(0.010)\end{array}$ & $\begin{array}{c}0.274^{* * *} \\
(0.011)\end{array}$ & $\begin{array}{c}0.237 * * * \\
(0.011)\end{array}$ & $\begin{array}{c}0.269 * * * \\
(0.012)\end{array}$ & $\begin{array}{c}0.287 * * * \\
(0.013)\end{array}$ & $\begin{array}{c}0.277 * * * \\
(0.012)\end{array}$ \\
\hline Special Offer Other Products & $\begin{array}{c}-0.077^{* * * *} \\
(0.004)\end{array}$ & $\begin{array}{c}-0.075^{* * *} \\
(0.005)\end{array}$ & $\begin{array}{c}-0.077 * * * \\
(0.004)\end{array}$ & $\begin{array}{c}-0.100 * * * \\
(0.005)\end{array}$ & $\begin{array}{c}-0.102^{* * *} \\
(0.006)\end{array}$ & $\begin{array}{c}-0.098 * * * \\
(0.005)\end{array}$ \\
\hline Constant & $\begin{array}{c}1.042 * * * \\
(0.096)\end{array}$ & $\begin{array}{c}1.242^{* * *} \\
(0.103)\end{array}$ & $\begin{array}{c}0.729 * * * \\
(0.101)\end{array}$ & $\begin{array}{c}1.164 * * * \\
(0.117)\end{array}$ & $\begin{array}{c}1.378 * * * \\
(0.127)\end{array}$ & $\begin{array}{c}1.300 * * * \\
(0.123)\end{array}$ \\
\hline Observations & 154617 & 141522 & 154617 & 100361 & 87266 & 100361 \\
\hline R-squared & 0.258 & 0.263 & 0.258 & 0.244 & 0.249 & 0.244 \\
\hline Number of items & 40 & 40 & 40 & 29 & 29 & 29 \\
\hline
\end{tabular}

${ }^{8}$ Trend $_{t}$ is divided by 1000 to make coefficients more readable. 


\subsection{Heterogeneous Effects across Consumers with Different Socio-Economic Characteristics}

The reactions of consumers to negative media coverage may differ in relation to their socio-economic characteristics. For example, more educated customers may better understand that the risk of product safety may not concern exclusively those brands mentioned by the media, but may signal a more general problem involving the whole product category. On the other hand, consumers with different characteristics may pay more or less attention to this type of news or devote more or less time to the choice of brand. ${ }^{9}$

Unfortunately, we do not have direct information on consumers' characteristics. Nevertheless, since consumers tend to buy food products in the area in which they live and we know the exact location of each store included in our dataset, we use as an indicator of consumers' socio-economic characteristics the house prices of the area in which the store is located. House prices for different towns and for different neighbors within the same town are taken from an agency of the Italian Ministry of the Economy (http://www.agenziaterritorio.it/), which has the aim is of monitoring the house market.

Under the assumption of a positive correlation between consumer income and house prices, we run separate regressions for stores located in areas where the price of houses is above the average price (€4,534 for squared meter) and for stores located in areas where the price of houses is below the average price. In addition, since some of the stores in our sample are located in Rome, while others are located in neighboring villages, we have also experimented splitting our sample according to this aspect. Results are reported in Table 4.

As shown in column 1 of Table 4, consumers living in richer areas, as a reaction to the fraud, have reduced the consumption of items produced both by involved and not involved brands. These consumers seem to have perceived the negative news on product quality as an industry-wide problem due to an inadequacy of the production process. On the other hand, as reported in column 2, consumers living in poorer areas have reduced their demand for items produced by the involved brands, but have increased their purchases of items produced by not involved brands.

Comparing the magnitude of the coefficients on the variables Post $t_{t}$ and Post $_{t}{ }^{*}$ InvolvedBrands $_{i}$, it emerges that the reaction to negative media coverage of consumers living in richer areas (column 1) is much smaller compared to the reaction of consumers living in poorer areas (column 2).

Columns 3 and 4 report estimation results, respectively, for stores located in Rome and for stores located in neighboring villages. It emerges that, after the negative publicity, purchases have

\footnotetext{
${ }^{9}$ Burton et al. (1996) show that changes in meat consumption over time in UK depends on consumer
} characteristics. 
increased for not involved brands and have decreased for involved ones, both for stores located in Rome and for stores located in villages near Rome. The reaction of consumers living in Rome seems to be smaller compared to the reaction of consumers living in neighboring villages. This could be due both to the fact that consumers living in town are richer (see above) and to the fact that information sharing is more frequent in small communities where people interact more frequently.

Table 4. Heterogeneous consumers' responses to negative media coverage according to socioeconomic characteristics. Dependent Variable: the natural log of the quantity of grated cheese

(1)

\begin{tabular}{|c|c|c|c|c|}
\hline Price per gram (in log) & $\begin{array}{c}-1.112 * * * \\
(0.026)\end{array}$ & $\begin{array}{c}-1.247 * * * \\
(0.038)\end{array}$ & $\begin{array}{c}-1.224 * * * \\
(0.023)\end{array}$ & $\begin{array}{c}-0.966 * * * \\
(0.062)\end{array}$ \\
\hline Post & $\begin{array}{c}-0.018 * * \\
(0.009)\end{array}$ & $\begin{array}{c}0.173^{* * *} \\
(0.007)\end{array}$ & $\begin{array}{c}0.073^{* * *} \\
(0.007)\end{array}$ & $\begin{array}{c}0.143^{* * *} \\
(0.008)\end{array}$ \\
\hline Post*(Involved Brands) & $\begin{array}{c}-0.046 * * * \\
(0.012)\end{array}$ & $\begin{array}{c}-0.223^{* * *} \\
(0.011)\end{array}$ & $\begin{array}{c}-0.108 * * * \\
(0.010)\end{array}$ & $\begin{array}{c}-0.192 * * * \\
(0.016)\end{array}$ \\
\hline Special Offer & $\begin{array}{c}0.242 * * * \\
(0.015)\end{array}$ & $\begin{array}{c}0.373^{* * *} \\
(0.015)\end{array}$ & $\begin{array}{c}0.278 * * * \\
(0.011)\end{array}$ & $\begin{array}{c}0.408 * * * \\
(0.023)\end{array}$ \\
\hline Special Offer Other Products & $\begin{array}{c}-0.106 * * * \\
(0.006)\end{array}$ & $\begin{array}{c}-0.058 * * * \\
(0.006)\end{array}$ & $\begin{array}{c}-0.097 * * * \\
(0.005)\end{array}$ & $\begin{array}{c}-0.067 * * * \\
(0.009)\end{array}$ \\
\hline Constant & $\begin{array}{c}2.808 * * * \\
(0.194)\end{array}$ & $\begin{array}{c}0.324^{*} \\
(0.172)\end{array}$ & $\begin{array}{c}1.222^{* * *} \\
(0.101)\end{array}$ & $\begin{array}{c}0.995 * * * \\
(0.285)\end{array}$ \\
\hline Observations & 75353 & 79264 & 112924 & 41693 \\
\hline R-squared & 0.230 & 0.323 & 0.273 & 0.275 \\
\hline Number of items & 31 & 40 & 40 & 33 \\
\hline
\end{tabular}

\section{Price Responses to Negative Media Coverage}

In the previous sections we have estimated consumers' reactions to negative media coverage taking as constant the price level. However, both producers and retailers can try to adopt price strategies aimed at reducing the negative impact produced by the negative news on product quality. For example, they may cut the price of their products and try in this way to prevent a demand reduction. ${ }^{10}$

In this section we analyze how retailer prices and margins on both Involved and Not Involved Brands have been affected by the negative publicity.

Firstly, we focus our attention on retailer prices. As shown in column 1 of Table 5, after the negative media coverage, retailer prices have increased both for not involved brands and for involved brands, but the increase for involved brands has been much smaller. The increase for not involved brands has been of $8.4 \%$, while the increase for involved brands has been $3.6 \%$. This difference is statistically significant.

In column 2 are reported results of a Linear Probability Model considering as dependent variable the dummy for items on Special Offer. The coefficients on Post $_{t}$ and Post ${ }_{t}^{*}$ InvolvedBrands $_{i}$

\footnotetext{
${ }^{10}$ They can also invest in advertising and try to regain customers' trust.
} 
are positive, implying that after the negative media coverage the probability of placing an item on Special Offer has increased for all brands, but the increase has been higher for involved brands (1.8 percentage points for not involved brands and 2.5 percentage points for involved brands).

These results show that the retailer prices have been negatively affected by the negative news on cheese quality. To investigate whether the negative media coverage has determined a reduction in the per unit gross profits made by the retailer, in column 3 we have considered as dependent variable the difference between the log of retailer price and the log of retailer cost (Margin). In this way we are able to investigate how the negative media coverage has affected the retailers' margins both on involved and not involved brands. From our estimates, it emerges that the Margin has increased for not involved brands (+4.3\%), while a reduction has been faced for involved ones $(-2.1 \%)$.

Very similar results are obtained when instead of considering the dummy Post $t_{t}$, we use the variable Trend ${ }_{t}$. As shown in column 4, prices were rising over time until July 2008 both for involved and not involved brands. On the other hand, we observe a positive coefficient on the interaction term Trend $_{t}{ }^{*}$ Post $_{t}$ and a negative coefficient on the interaction term Trend $_{t}{ }^{*}$ Post $_{t}{ }^{*}$ InvolvedBrands $_{i}$, implying that after the negative media coverage, retailer prices continued to rise over time, but the increase was much smaller for the prices of items produced by brands directly affected by the negative publicity. Results reported in column 5 confirm that the cost of the negative shock was not borne exclusively by the producers. Indeed, it emerges that the margins gained by retailers on the items produced by Involved Brands have reduced after the adverse publicity.

Table 5. Price and Margin responses to negative media coverage.

\begin{tabular}{|c|c|c|c|c|c|c|}
\hline & $\begin{array}{c}\text { (1) } \\
\text { Price (in log) }\end{array}$ & $\begin{array}{c}(2) \\
\text { Special } \\
\text { Offer }\end{array}$ & $\begin{array}{c}(3) \\
\text { Margin }\end{array}$ & $\begin{array}{c}\text { (4) } \\
\text { Price (in log) }\end{array}$ & $\begin{array}{c}(5) \\
\text { Special } \\
\text { Offer }\end{array}$ & $\begin{array}{c}(6) \\
\text { Margin }\end{array}$ \\
\hline Post & $\begin{array}{c}0.084 * * * \\
(0.001)\end{array}$ & $\begin{array}{c}0.018 * * * \\
(0.002)\end{array}$ & $\begin{array}{c}0.043 * * * \\
(0.001)\end{array}$ & & & \\
\hline Post*(Involved Brands) & $\begin{array}{c}-0.048 * * * \\
(0.001)\end{array}$ & $\begin{array}{c}0.007^{* *} \\
(0.003)\end{array}$ & $\begin{array}{c}-0.064 * * * \\
(0.001)\end{array}$ & & & \\
\hline Trend & & & & $\begin{array}{c}0.044^{* * *} \\
(0.001)\end{array}$ & $\begin{array}{c}0.033 * * * \\
(0.003)\end{array}$ & $\begin{array}{c}0.006^{* * *} \\
(0.001)\end{array}$ \\
\hline Trend Post Fraud & & & & $\begin{array}{c}0.031 * * * \\
(0.001)\end{array}$ & $\begin{array}{c}-0.004 * * \\
(0.002)\end{array}$ & $\begin{array}{c}0.025^{* * *} \\
(0.001)\end{array}$ \\
\hline Trend*(Involved Brands) & & & & $\begin{array}{c}0.097 * * * \\
(0.002)\end{array}$ & $\begin{array}{c}-0.079 * * * \\
(0.005)\end{array}$ & $\begin{array}{c}0.037 * * * \\
(0.002)\end{array}$ \\
\hline $\begin{array}{l}\text { Trend*(Period Post } \\
\text { Fraud)*(Involved Brands) }\end{array}$ & & & & $-0.085^{* * *}$ & $0.046 * * *$ & $-0.061^{* * *}$ \\
\hline Constant & $\begin{array}{c}-4.377^{* * *} \\
(0.002)\end{array}$ & $\begin{array}{c}0.070 * * * \\
(0.005)\end{array}$ & $\begin{array}{c}0.356 * * * \\
(0.002)\end{array}$ & $\begin{array}{c}(0.001) \\
-4.430 * * * \\
(0.002)\end{array}$ & $\begin{array}{c}(0.003) \\
0.069 * * * \\
(0.005)\end{array}$ & $\begin{array}{c}(0.001) \\
0.342^{* * *} \\
(0.002)\end{array}$ \\
\hline Observations & 154619 & 154619 & 154618 & 154619 & 154619 & 154618 \\
\hline R-squared & 0.229 & 0.012 & 0.156 & 0.266 & 0.014 & 0.161 \\
\hline Number of items & 40 & 40 & 40 & 40 & 40 & 40 \\
\hline
\end{tabular}




\section{Robustness Checks: Weekly and Monthly Data}

In the previous analysis we have considered daily purchases. However, in our dataset we have no observations when purchases in a given day for a certain item and a certain store are equal to zero. This implies that when the demand of an item falls to zero we are not able to use this observation in our analysis. Even if we expect these missing values to be not particularly relevant for our analysis, as a robustness check we have aggregated our observations alternatively on weekly and on monthly basis. More precisely, for all the variables of interest we have taken respectively the weekly and the monthly average. With this type of aggregation of the data, missing values for zero purchases should be very rare. In fact, the spell of time considered is long enough to allow the record of at least one purchase for each item.

In Table 6 are reported estimates of the medium run effects of the negative media coverage on purchases, prices and margins. In columns 1, 2 and 3 we use weekly data, while in columns 4, 5 and 6 are reported estimates based on monthly data. All in all, it emerges that, also using weekly or monthly data, the results discussed in the previous sections remain substantially unchanged. The negative publicity has produced a reduction of the demand for items sold by involved brands. The consumers have substituted the demand of the items produced by these brands with the products of not involved brands (see Table 6, columns 1 and 4).

The negative media coverage has also affected price decisions by producers and retailers: even if after July 2008 prices have increased both for not involved brands and involved brands, the increase for involved brands has been much smaller (columns 2 and 4). Results again confirm that the margin obtained by retailers on involved brands has reduced in response to the negative media coverage.

Table 6. The medium-run consumers' responses to negative media coverage with data aggregated at weekly (columns 1-3) and monthly (columns 4-6) level

\begin{tabular}{|c|c|c|c|c|c|c|}
\hline & \multicolumn{3}{|c|}{ Weekly Data } & \multicolumn{3}{|c|}{ Monthly Data } \\
\hline & (1) & $(2)$ & (3) & (4) & (5) & (6) \\
\hline & $\begin{array}{l}\text { Quantity } \\
\text { (in log) }\end{array}$ & $\begin{array}{l}\text { Price (in } \\
\text { log) }\end{array}$ & Margin & $\begin{array}{l}\text { Quantity } \\
\text { (in log) }\end{array}$ & $\begin{array}{l}\text { Price (in } \\
\text { log) }\end{array}$ & Margin \\
\hline Price per gram (in log) & $\begin{array}{c}-1.208 * * * \\
(0.033)\end{array}$ & & & $\begin{array}{c}-1.149 * * * \\
(0.056)\end{array}$ & & \\
\hline Post & $\begin{array}{c}0.091^{* * *} \\
(0.008)\end{array}$ & $\begin{array}{c}0.083^{* * *} \\
(0.002)\end{array}$ & $\begin{array}{c}0.045^{* * *} \\
(0.002)\end{array}$ & $\begin{array}{c}0.083^{* * *} \\
(0.014)\end{array}$ & $\begin{array}{c}0.087 * * * \\
(0.003)\end{array}$ & $\begin{array}{c}0.050^{* * *} \\
(0.003)\end{array}$ \\
\hline Post*(Involved Brands) & $\begin{array}{c}-0.143^{* * *} \\
(0.012)\end{array}$ & $\begin{array}{c}-0.035^{* * *} \\
(0.003)\end{array}$ & $\begin{array}{c}-0.057 * * * \\
(0.003)\end{array}$ & $\begin{array}{c}-0.129 * * * \\
(0.019)\end{array}$ & $\begin{array}{c}-0.037 * * * \\
(0.006)\end{array}$ & $\begin{array}{c}-0.061^{* * *} \\
(0.005)\end{array}$ \\
\hline Observations & 30332 & 30332 & 30331 & 7491 & 7491 & 7490 \\
\hline R-squared & 0.406 & 0.238 & 0.158 & 0.482 & 0.275 & 0.190 \\
\hline Number of items & 40 & 40 & 40 & 40 & 40 & 40 \\
\hline
\end{tabular}




\section{Concluding Remarks}

In this paper we have investigated whether negative media coverage about a firm product quality determines goodwill losses and induces consumers to switch to other brands or reduce the demand for the whole product category.

We have focused our attention on the negative news appeared in the Italian press and on TV news in July 2008 and concerning the quality of cheese of some brands. Using scanner data recording daily consumers' purchases, we have analyzed the effects of the negative media coverage adopting a difference-in-differences estimation strategy, which exploits the fact that only a certain number of brands were directly exposed to adverse publicity. We have investigated both the short and the medium run effects of the negative publicity by comparing changes in the average sales of brands receiving negative media attention with the sales of brands not directly mentioned by media. The results of our econometric investigation show that during the period in which the negative news appeared in the media, consumers have significantly reduced their demand for items sold by brands receiving negative publicity, while they have increased demand for products sold by competitor brands.

These effects tend to persist over time also when the media is no more devoting attention to the issue. The medium-run effects of the negative publicity appear to be stronger than the short-run effects, maybe because it takes time for the information to disseminate among consumers. Furthermore, we have found that brands receiving negative publicity had to reduce the prices of their products, vis-à-vis other competing brands.

From our analysis it emerges that reputational losses deriving from the diffusion of negative news on product quality have been quite relevant: consumers have significantly reduced purchases of brands receiving adverse publicity for quite a long time and, in addition, firms had to lower their prices.

On the one hand, this represents an encouraging result, since it suggests that reputational mechanisms are in place and that markets are able to deter opportunistic firms from producing faulty or low quality products. On the other hand, since the news reported by the press may not reflect an effective involvement of the brands receiving negative publicity (the Court evaluating the case has not reached a verdict yet), these results - showing a strong reaction of consumers to news reported by media - pose some important concerns on consumer persuasion (see DellaVigna and Gentzkow, 2009) and on media reliability. 


\section{References}

Askitas, N. and Zimmermann K. (2009), “Google Econometrics and Unemployment Forecasting”, Applied Economics Quarterly, 55 (2), pp. 107-129.

Borenstein, S. and Zimmerman, M., (1988) "Market Incentives for Safe Commercial Airline Operation”, American Economic Review, 78(5), pp. 913-935.

Burton, M., Dorsett, R., Young, T., (1996), "Changing preferences for meat: Evidence from UK household data, 1973-93," European Review of Agricultural Economics, 23 (3), 357-370.

Choi, H. and Varian, H. (2009), "Predicting Initial Claims for Unemployment Benefits",Google technical report.

D’Amuri F., and Marcucci, (2009), "Google it! Forecasting the US unemployment rate with a Google job search index", ISER, University of Essex.

Dahlgran, R. and Fairchild, D. (2002), "The demand impacts of chicken contamination publicity - a case study”, Agribusiness, 18(4), pp.459-474.

Darby M. and Karni E. (1973), "Free Competition and the Optimal Amount of Fraud”, Journal of Law and Economics, 16 (1), pp. 67-70.

DellaVigna, S. and Gentzkow, M., 2009, "Persuasion: Empirical Evidence”, Annual Review of Economics, vol. 2.

Emons W. (2001), “Credence goods monopolists”, International Journal of Industrial Organization, 19 (3-4), pp. 375-389.

Erdem, T. and Swaitt, J., (2004), "Brand credibility, brand consideration, and choice", Journal of Consumer Research, 31(June), pp. 191-198.

Feddersen T. and Gilligan T. (2001), "Saints and Markets: Activists and the Supply of Credence Goods”, Journal of Economics \& Management Strategies, 10 (1), pp. 149-171.

Garber, S. and Adams, J., (1998), "Product and Stock Market Responses to Automotive Product Liability Verdicts”, Brookings Papers on Economic Activity, Microeconomics, pp. 1-53.

Ginsberg, J., Mohebbi, M., Patel, R., Brammer, L., Smolinski, M., Brilliant, L. (2009), "Detecting Influenza Epidemics using Search Engine Query Data”, Nature, 457, pp. 1012-1014

Jarrell, G., and S. Peltzman (1985) 'The Impact of Product Recalls on the Wealth of Sellers', Journal of Political Economy, 93(3), pp. 512-536.

Klein, B. and Leffler, K. (1981), "The Role of Market Forces in Assuring Contractual Performance”, Journal of Political Economy, 89 (4), pp. 615-641.

Klein, J. and Dawar, N., (2004), "Corporate social responsibility and consumers' attributions and brand evaluations in a product-harm crisis". International Journal of Research in Marketing, 21, pp. 203-217.

Nelson P., (1974), “Advertising as Information”, Journal of Political Economy, 82(4), pp. 729-740.

Prince, D. and Rubin, P., (2002), "The Effects of Product Liability Litigation on the Value of Firms", American Law and Economics Review. 4 (1), pp. 44-87.

Schlenker, W., and Villas-Boas, S., (2008), "Consumer and Market Responses to Mad-Cow Disease”, UC Berkeley: Department of Agricultural and Resource Economics, Working Paper N. 1023.

Shapiro C., (1983), “Optimal Pricing of Experience Goods”, Bell Journal of Economics, 14(2), pp. 497-507.

Shimshack, J., Ward, M., and Beatty, T., (2007) "Mercury Advisories: Information, Education, and Fish Consumption," Journal of Environmental Economics and Management, 53 (2), 158\{179.

Smith, M., E. van Ravenswaay, and Thompson, S., (1988) "Sales Loss Determination in Food Contamination Incidents: An Application to Milk Bans in Hawaii”, American Journal of Agricultural Economics, 70 (3), 513-520.

Suhoy, T. (2009) "Query Indices and a 2008 Downturn ”, Bank of Israel Discussion Paper.

Takaoka, S., (2004), "Verdicts and the value of the firm in Japan”, Economics Letters, 84, 1, pp. 9397.

Viscusi, W. and Hersch, J. (1990), "The Market Response to Product Safety Litigation," Journal of Regulatory Economics, 2(3), pp. 215-30 